\title{
Numerical Study of the Gas Distribution in an Oxygen Blast Furnace. Part 1: Model Building and Basic Characteristics
}

\author{
ZONGLIANG ZHANG,${ }^{1}$ JIALE MENG,${ }^{1}$ LEI GUO, ${ }^{1}$ \\ and ZHANCHENG GUO ${ }^{1,2}$
}

\begin{abstract}
1.-State Key Laboratory of Advanced Metallurgy, University of Science and Technology Beijing, Haidian District, Beijing 100083, People’s Republic of China. 2.—e-mail: zcguo@metall.ustb. edu.cn
\end{abstract}

Based on multifluid theory, transport phenomena theory, metallurgical reaction kinetics, thermodynamics, and computational fluid dynamics, a multifluid model for an oxygen blast furnace was established to evaluate the gas distribution in a furnace. The uneven distribution of recycling gas in oxygen blast furnaces was found to be a severe problem. This uneven distribution resulted from injecting a large amount of recycling gas into the furnace shaft. Gas distribution substantially affects the energy and heat utilization of an oxygen blast furnace. Therefore, the basic characteristics of the gas distribution in an oxygen blast furnace are illustrated. The results show that in the top of the oxygen blast furnace, the concentration differences of the $\mathrm{CO}$ and $\mathrm{CO}_{2}$ between the center and edge reach $7.8 \%$ and $11.7 \%$, respectively. The recycling gas from the shaft tuyere only penetrates to two thirds the length of the radius.

\section{INTRODUCTION}

Approximately two thirds of the global annual steel production utilizes a long blast furnace process. Therefore, blast furnaces play a significant role in the steel industry. However, this process involves high energy consumption, heavy environmental pollution, and high $\mathrm{CO}_{2}$ emission, putting tremendous pressure on both the energy sector and the environment. Furthermore, the energy-saving potential of traditional blast furnace technologies has reached a limit. Fortunately, oxygen blast furnace ironmaking ${ }^{1,2}$ can reduce more than $70 \%$ of the coke consumption, $11.1 \%$ of the energy consumption, and $59.6 \%$ of the $\mathrm{CO}_{2}$ emissions. This process can significantly improve the energy conservation and reduce environmental pollution by transforming a traditional blast furnace. A variety of specific oxygen blast furnace processes have been proposed, among which the gasification furnace-full oxygen blast furnace (GF-FOBF) process ${ }^{3}$ (Fig. 1) displays unique advantages because of the reforming and heating effects of the gasification furnace. The gasification furnace provides safe, adequate, and stable recycling gas.

The ironmaking process involves many complex chemical reactions and flow, phase change, heat transfer, mass transfer, and momentum transfer phenomena. Additionally, the internal processes are nearly unmeasurable because of the high temperature and closed nature of ironmaking. Therefore, the blast furnace is considered to be the most complex reactor in the metallurgy field. To study the internal processes and phenomena of a blast furnace, numerous methods have been proposed, such as a dissection investigation of blast furnaces ${ }^{4}$ and installing sensors in the inner wall of blast furnaces. ${ }^{5}$ However, a dissection investigation of blast furnaces is expensive in terms of time and investment; sensors can only provide limited discrete data, which is not sufficient for studying the comprehensive internal phenomena. Among the methods, the mathematical models display unique advantages, such as the multifluid model ${ }^{6,7}$ proposed in the 1990s. These models can simulate temperature, velocities, concentration fields, and distributions of other parameters through mathematical calculations that are based on chemical reactions, heat and mass transfers, and other complex phenomena within the blast furnace. Therefore, the situation inside the blast furnace can be more visually understood. Moreover, many important results derived from mathematical models have been applied in the production process. Previously, 
mathematical models have focused on traditional blast furnaces, and only a few models of oxygen blast furnaces have been reported. Oxygen blast furnaces such as the top-gas recycling blast furnace in the ultra-low $\mathrm{CO}_{2}$ steelmaking (ULCOS) project in the European Union $^{8}$ are currently in experimental and pilot-scale test stages. Additionally, limited numerical simulation studies are available concerning the internal phenomena of an oxygen blast furnace. ${ }^{9,10}$ The gas distribution in an oxygen blast furnace seriously affects its smooth operation, energy consumption, and $\mathrm{CO}_{2}$ emissions because the recycling gas carries a large amount of heat and reducing gas. The distribution of this gas affects the heat distribution in the blast furnace, which is significant for energy conservation and environmental protection. However, no detailed descriptions are available for the gas distribution in an oxygen blast furnace or for the related influencing factors. In Part 1 of this study, the gas distribution in the oxygen blast furnace was studied with a multifluid mathematical model, and the basic characteristics of the gas distribution in an oxygen blast furnace were summarized. Based on the findings of the first

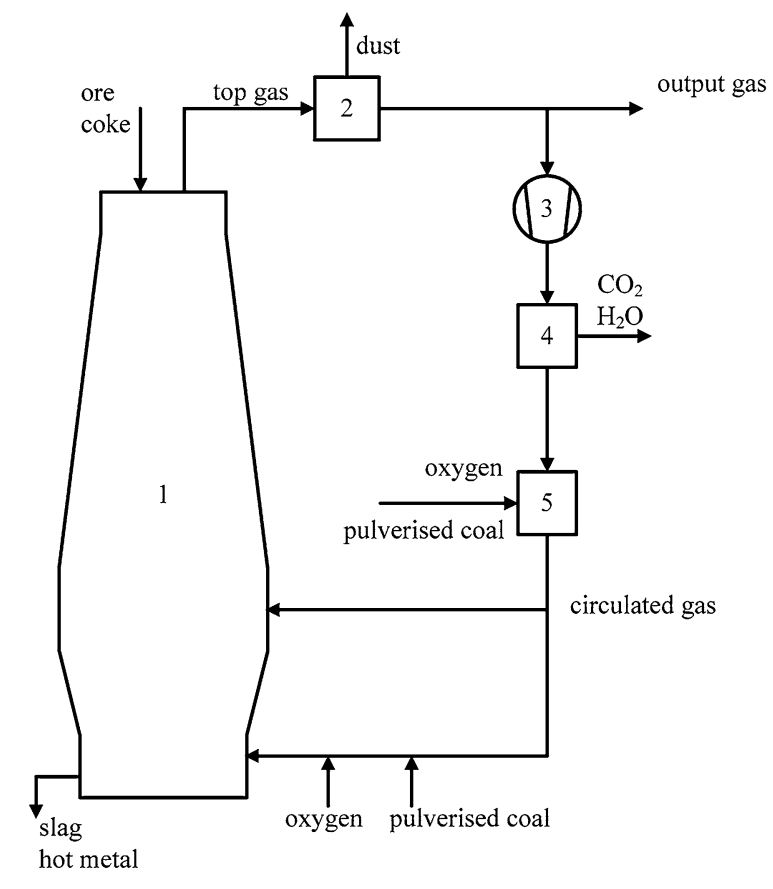

1-blast furnace;2-dust collector;3-compressor;4- $\mathrm{CO}_{2}$ removal unit;5-gasifier

Fig. 1. The schematic diagram of the GF-FOBF process. part, the influence of the design and operating parameters was investigated in Part 2 to further optimize the gas distribution. The multifluid mathematical model considered three phases: complex chemical reactions, heat and momentum transfer, and other processes. Therefore, this model is considered to be superior to most models that use two phases and limited chemical reactions, ensuring the validity of the results.

\section{MODEL DESCRIPTION}

\section{Assumptions}

To facilitate model building and numerical simulation, the following was assumed:

1. Only gas, solid, and liquid phases were considered; the fines in blast furnace were ignored.

2. The coal injected into the blast furnace through the hearth tuyere was converted into substances such as $\mathrm{CO}, \mathrm{CO}_{2}$, and $\mathrm{H}_{2} \mathrm{O}$ under high temperatures.

3. Insignificant substances and reactions were ignored.

4. The furnace top pressure was set to $1.2 \times 10^{5} \mathrm{~Pa}$.

5. The cohesive zone was defined as the region in which the solid temperature was $1373 \mathrm{~K}$ to $1673 \mathrm{~K}$.

6. The blast furnace inner shape, tuyere positions, and inner states were symmetrically distributed.

\section{Phases and Reactions Involved in the Model}

The substances in the blast furnace are divided into three phases in the model. ${ }^{11,12}$ The phases and substances involved in the model are shown in Table I.

Table II shows the 12 chemical reactions and three phase transitions in the model. In this model, the indirect reduction reaction of iron ore is calculated using the unreacted core model.

\section{Model Framework}

The complexity of a blast furnace lies in the chemical reactions and phase interactions, including the heat and momentum exchanges among gas, solid, and liquid phases. The material behavior in the blast furnace follows three laws: conservations of mass, conservation of momentum, and conservation of energy. To facilitate computer programming,

Table I. Phases and substances involved in the model

\begin{tabular}{lc}
\hline Phases & Substances \\
$\begin{array}{l}\text { Gas } \\
\text { Solid } \\
\text { Liquid }\end{array}$ & $\mathrm{CO}, \mathrm{CO}_{2}, \mathrm{H}_{2}, \mathrm{H}_{2} \mathrm{O}, \mathrm{N}_{2}, \mathrm{O}_{2}$ \\
\hline
\end{tabular}


Table II. Chemical reactions and phase transitions involved in the model

\begin{tabular}{|c|c|c|}
\hline$n$ & Reactions & Description \\
\hline 1 & $3 \mathrm{Fe}_{2} \mathrm{O}_{3}(\mathrm{~s})+\mathrm{CO}(\mathrm{g})=2 \mathrm{Fe}_{3} \mathrm{O}_{4}(\mathrm{~s})+\mathrm{CO}_{2}(\mathrm{~g})$ & $\mathrm{CO}$ indirect reduction reactions \\
\hline 2 & $w /(4 w-3) \mathrm{Fe}_{3} \mathrm{O}_{4}(\mathrm{~s})+\mathrm{CO}(\mathrm{g})=3 /(4 w-3) \mathrm{Fe}_{w} \mathrm{O}(\mathrm{s})+\mathrm{CO}_{2}(\mathrm{~g})$ & \\
\hline 3 & $\mathrm{Fe}_{w} \mathrm{O}(\mathrm{s})+\mathrm{CO}(\mathrm{g})=w \mathrm{Fe}(\mathrm{s})+\mathrm{CO}_{2}(\mathrm{~g})$ & \\
\hline 4 & $3 \mathrm{Fe}_{2} \mathrm{O}_{3}(\mathrm{~s})+\mathrm{H}_{2}(\mathrm{~g})=2 \mathrm{Fe}_{3} \mathrm{O}_{4}(\mathrm{~s})+\mathrm{H}_{2} \mathrm{O}(\mathrm{g})$ & $\mathrm{H}_{2}$ indirect reduction reactions \\
\hline 5 & $w /(4 w-3) \mathrm{Fe}_{3} \mathrm{O}_{4}(\mathrm{~s})+\mathrm{H}_{2}(\mathrm{~g})=3 /(4 w-3) \mathrm{Fe}_{w} \mathrm{O}(\mathrm{s})+\mathrm{H}_{2} \mathrm{O}(\mathrm{g})$ & \\
\hline 6 & $\mathrm{Fe}_{w} \mathrm{O}(\mathrm{s})+\mathrm{H}_{2}(\mathrm{~g})=w \mathrm{Fe}(\mathrm{s})+\mathrm{H}_{2} \mathrm{O}(\mathrm{g})$ & \\
\hline $7 \mathrm{a}$ & $\mathrm{Fe}_{w} \mathrm{O}(\mathrm{l})+\mathrm{C}(\mathrm{s})=w \mathrm{Fe}(\mathrm{l})+\mathrm{CO}($ absorbed on $\mathrm{l})$ & Direct reduction reactions \\
\hline $7 \mathrm{~b}$ & $\mathrm{CO}($ absorbed on $\mathrm{l})=\mathrm{CO}(\mathrm{g})$ & \\
\hline 8 & $\mathrm{C}(\mathrm{s})+\mathrm{CO}_{2}(\mathrm{~g})=2 \mathrm{CO}(\mathrm{g})$ & Boudouard reaction \\
\hline 9 & $\mathrm{C}(\mathrm{s})+\mathrm{H}_{2} \mathrm{O}(\mathrm{g})=\mathrm{CO}(\mathrm{g})+\mathrm{H}_{2}(\mathrm{~g})$ & Water gas reaction \\
\hline 10 & $\mathrm{C}(\mathrm{s})+1 / 2 \mathrm{O}_{2}(\mathrm{~g})=\mathrm{CO}(\mathrm{g})$ & Incomplete combustion reaction \\
\hline 11 & $\mathrm{C}(\mathrm{s})+\mathrm{O}_{2}(\mathrm{~g})=\mathrm{CO}_{2}(\mathrm{~g})$ & Complete combustion reaction \\
\hline 12 & $\mathrm{CO}(\mathrm{g})+\mathrm{H}_{2} \mathrm{O}(\mathrm{g})=\mathrm{CO}_{2}(\mathrm{~g})+\mathrm{H}_{2}(\mathrm{~g})$ & Vapor conversion reaction \\
\hline 13 & $\mathrm{Fe}(\mathrm{s})=\mathrm{Fe}(\mathrm{l})$ & Melting phase change \\
\hline 14 & $\mathrm{Fe}_{w} \mathrm{O}(\mathrm{s})=\mathrm{Fe}_{w} \mathrm{O}(\mathrm{l})$ & \\
\hline 15 & Gangue $(s)=$ Slag $(1)$ & \\
\hline
\end{tabular}

these conservation laws are represented in a unified form, as seen in Eq. 1.

$$
\frac{\partial\left(\varepsilon_{i} \rho_{i} \psi\right)}{\partial t}+\operatorname{div}\left(\varepsilon_{i} \rho_{i} \boldsymbol{U} \psi\right)=\operatorname{div}\left(\varepsilon_{i} \Gamma_{\psi} \operatorname{grad} \psi\right)+\boldsymbol{S}_{\psi}
$$

where $\varepsilon_{i}$ is the volume fraction of phase $i$ in the blast furnace; $\rho_{i}$ is the fluid density of phase $i, \mathrm{~kg} \mathrm{~m}^{-3} ; \boldsymbol{U}$ is the velocity vector of phase, $\mathrm{m} \mathrm{s}^{-1} ; \psi$ is the universal variable of the conservation equation; $\Gamma_{\psi}$ is the generalized diffusion coefficient; and $S_{\psi}$ is the generalized source term. Among these variables, $\psi$ can represent $u, v, w, H$, and other solution variables.

\section{Interphase Transfer of Momentum and Heat}

Because the phases and materials in the oxygen blast furnace model have been simplified, the interphase momentum exchanges involved in the model include interactions among three phases. The gas-solid, gas-liquid, and solid-liquid interaction forces can be calculated using Eqs. 2, 3, and 4, namely the Ergun equation, ${ }^{13}$ Richardson-Zaki equation, ${ }^{14}$ and Kozeny-Carmen equation. ${ }^{15}$

$$
\tilde{F}_{\mathrm{gs}}=150 \frac{\mu_{\mathrm{g}}\left(1-\varepsilon_{\mathrm{g}}\right)^{2}\left(\tilde{u}_{\mathrm{g}}-\tilde{u}_{\mathrm{s}}\right)}{\varepsilon_{\mathrm{g}}^{2} \mathrm{~d}_{\mathrm{s}}^{2} \phi_{\mathrm{s}}^{2}}+1.75 \frac{\rho_{\mathrm{g}}\left(1-\varepsilon_{\mathrm{g}}\right)\left(\tilde{u}_{\mathrm{g}}-\tilde{u}_{\mathrm{s}}\right)^{2}}{\varepsilon_{\mathrm{g}} \mathrm{d}_{\mathrm{s}} \phi_{\mathrm{s}}}
$$

$$
\begin{gathered}
\tilde{F}_{\mathrm{gl}}=-C_{D \mathrm{gl}}\left(\frac{3 \varepsilon_{\mathrm{l}} \rho_{\mathrm{l}}}{4 \mathrm{~d}_{\mathrm{l}} \phi_{\mathrm{l}}}\right)\left|\tilde{u}_{\mathrm{g}}-\tilde{u}_{\mathrm{l}}\right|\left(\tilde{u}_{\mathrm{g}}-\tilde{u}_{\mathrm{l}}\right) \\
\tilde{F}_{\mathrm{sl}}=\frac{\rho_{\mathrm{l}}}{r_{h}}\left|\tilde{u}_{\mathrm{s}}-\tilde{u}_{1}\right|\left(5 \beta+0.4 \beta^{0.1}\right)\left(\tilde{u}_{\mathrm{s}}-\tilde{u}_{1}\right)
\end{gathered}
$$

where

$$
\beta=\frac{\mu_{\mathrm{l}}}{\rho_{\mathrm{l}}\left|\tilde{u}_{\mathrm{s}}-\tilde{u}_{\mathrm{l}}\right| r_{h}}
$$

$$
r_{h}=\frac{\varepsilon_{1} \phi_{\mathrm{s}} d_{\mathrm{s}}}{6 \varepsilon_{\mathrm{s}}}
$$

$\tilde{u_{i}}$ is the actual speed of phase $i, \mathrm{~m} \mathrm{~s}^{-1} ; \varphi_{s}$ is the shape factor of the solid particle; $C_{D g l}$ is the gasliquid interphase drag coefficient; $d_{s}$ is the solid particle diameter, $m ; d_{1}$ is the droplet diameter, $m$; and $\varphi_{l}$ is the droplet shape factor.

Similarly, the heat exchanges involved in the model include interactions among three phases. The gas-solid, gas-liquid, and solid-liquid heat transfers can be calculated using Eqs. 7, 8, and 9, namely the Ranz-Marshall equation, ${ }^{16}$ Mackey-Warner equation, ${ }^{17}$ and Eckert-Drake equation. ${ }^{18}$

$$
\begin{gathered}
\dot{E}_{\mathrm{gs}}=A_{\mathrm{gs}} h_{\mathrm{gs}}\left(T_{\mathrm{g}}-T_{\mathrm{s}}\right) \\
\dot{E}_{\mathrm{gl}}=A_{\mathrm{gl}} h_{\mathrm{gl}}\left(T_{\mathrm{g}}-T_{\mathrm{l}}\right) \\
\dot{E}_{\mathrm{sl}}=A_{\mathrm{sl}} h_{\mathrm{sl}}\left(T_{\mathrm{l}}-T_{\mathrm{s}}\right)
\end{gathered}
$$

where

$$
\begin{gathered}
A_{\mathrm{s}}=f_{\text {ore }} \frac{6 \varepsilon_{\text {ore }}}{d_{\text {ore }} \phi_{\text {ore }}}+f_{\text {coke }} \frac{6 \varepsilon_{\text {coke }}}{d_{\text {coke }} \phi_{\text {coke }}} \\
A_{\mathrm{gs}}=A_{\mathrm{s}}-A_{\mathrm{sl}}
\end{gathered}
$$




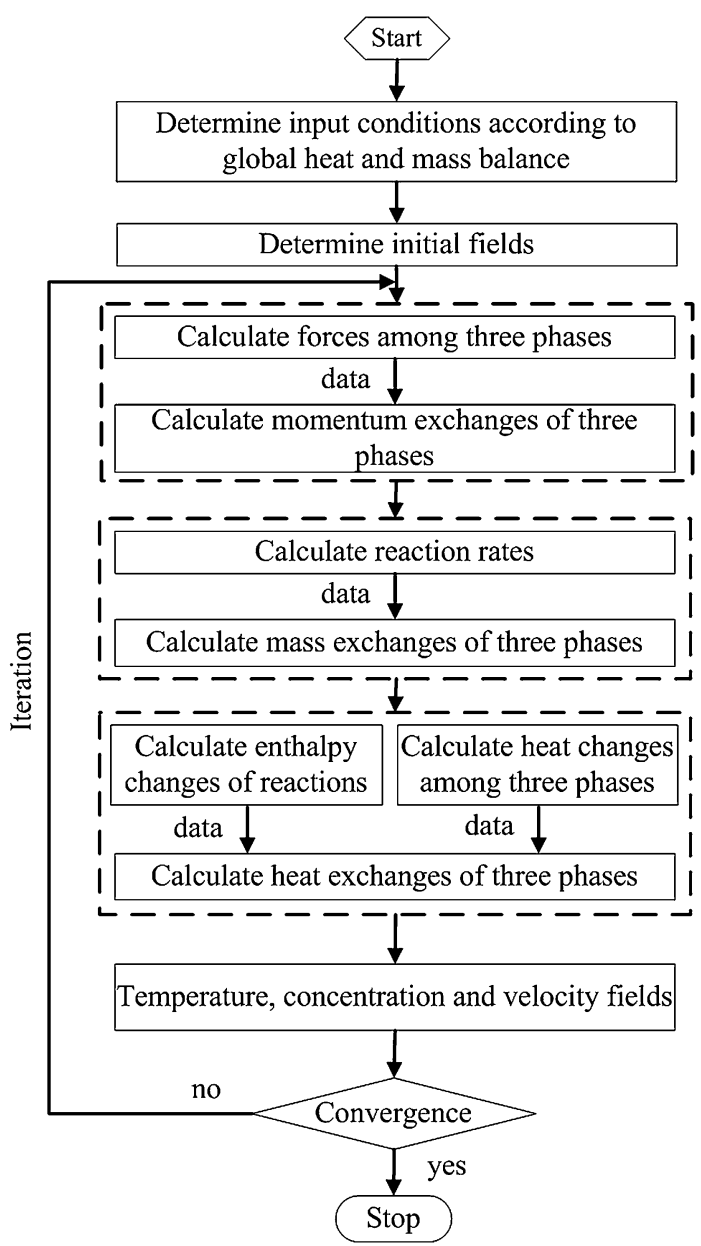

Fig. 2. Solution procedures for the multifluid model.

$\frac{A_{\mathrm{sl}}}{A_{\mathrm{s}}}=0.400 \mathrm{Re}_{\mathrm{sl}}^{0.218} \mathrm{We}_{\mathrm{sl}}^{0.0428} \mathrm{Fr}_{\mathrm{sl}}^{-0.0238}\left(1+\cos \theta_{\mathrm{sl}}\right)^{-0.0235}$

$$
h_{\mathrm{gs}}=\frac{k_{\mathrm{g}}}{d_{\mathrm{s}}}\left(2.0+0.39 \operatorname{Re}_{\mathrm{gs}}^{1 / 2} \underset{\mathrm{g}}{\operatorname{Pr}}\right)
$$

$A_{\mathrm{gl}} h_{\mathrm{gl}}=4.18\left[\varepsilon_{\mathrm{g}} \rho_{\mathrm{g}} \tilde{u}_{\mathrm{g}} C p_{\mathrm{g}}\left(\varepsilon_{\mathrm{l}} \tilde{u}_{\mathrm{l}}\right)^{0.35}\right] \operatorname{Re}_{\mathrm{gl}}^{-0.37}\left(\frac{S c_{\mathrm{g}}}{\operatorname{Pr}_{\mathrm{g}}}\right)^{2 / 3}$

$$
h_{1}=\frac{k_{1}}{d_{\mathrm{s}}}\left(\frac{2 \sqrt{\operatorname{Re}_{\mathrm{sl}} \operatorname{Pr}_{1}}}{1.55 \sqrt{\operatorname{Pr}_{1}}+3.09 \sqrt{0.372-0.15 \operatorname{Pr}_{1}}}\right)
$$

$$
h_{\mathrm{s}}=2 \sqrt{\frac{k_{\mathrm{s}} C p_{\mathrm{s}} \rho_{\mathrm{s}}\left|\tilde{u}_{1}-\tilde{u}_{\mathrm{s}}\right|}{\pi d_{\mathrm{s}}}}
$$

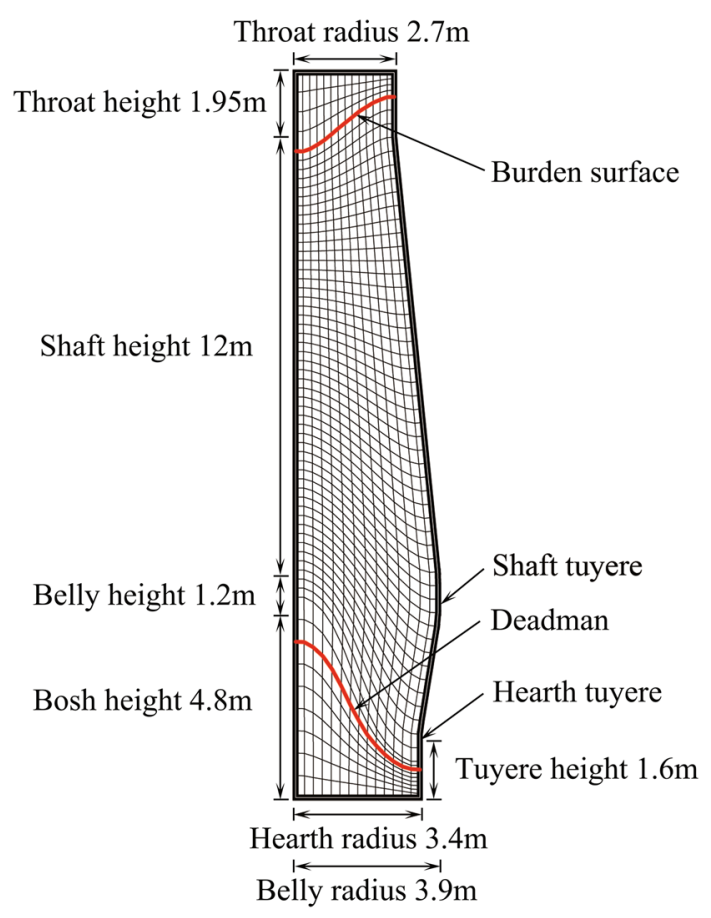

Fig. 3. Geometrical parameters and mesh distribution of the modeled blast furnace.

$$
\frac{1}{h_{\mathrm{sl}}}=\frac{1}{h_{\mathrm{s}}}+\frac{1}{h_{1}}
$$

$h_{i j}$ is the heat-transfer coefficient between phase $i$ and phase $j, W m^{-2} K^{-1}$; We $e_{i j}$ is the Weber number between phase $i$ and $j ; \theta_{i j}$ is the contact angle between phase $i$ and $j$, ${ }^{\circ} ; \mathrm{Fr}_{i j}$ is the Froude number between phase $i$ and $j$; and $k_{s}$ is the thermal conductivity of the solid phase, $W m^{-1} K^{-1}$.

\section{Boundary Conditions and Solving Strategies}

The boundary conditions of the three phases are different, and the specific settings are described below. For the gas phase, the gas composition and temperature at the tuyere are set as the components and temperature after reaction of pulverized coal and oxygen. At the outlet of the top furnace, the gas flow is fully developed. The furnace wall allows the gas phase to slide freely. For the solid phase, the composition and temperature of the solid phase at the burden surface are set according to the actual production parameters. The outlet of the solid phase was set at the bottom of the furnace wall, and the solid phase flow is fully developed in the outlet. In addition, the furnace wall and deadman produce some friction to the solid phase flow. The total heat loss of the furnace wall is allocated to the gas phase and solid phase. The heat losses of the furnace wall in the gas and solid energy source terms are calculated using Eq. 18. The furnace wall is a freely sliding interface for the liquid phase, and the liquid 
Table III. The operating parameters for the simulated traditional blast furnace

\begin{tabular}{|c|c|c|}
\hline Phases & $\begin{array}{c}\text { Operating } \\
\text { parameters }\end{array}$ & Values \\
\hline Gas & $\begin{array}{l}\text { Blast rate, blast } \\
\text { temperature, } \\
\text { humidity, oxygen } \\
\text { enrichment rate, } \\
\text { top pressure, and } \\
\text { blast pressure }\end{array}$ & $\begin{array}{c}1700 \mathrm{~m}^{3} \min ^{-1}, 1423 \mathrm{~K} \\
1.7 \%, 1.66 \%, 1.2 \times 10^{5} \mathrm{~Pa}, \\
\text { and } 2.2 \times 10^{5} \mathrm{~Pa}\end{array}$ \\
\hline Solid & $\begin{array}{l}\text { Daily output of iron, } \\
\mathrm{Fe}_{2} \mathrm{O}_{3} \text { content, coke } \\
\text { rate, fixed carbon } \\
\text { content of coke, } \\
\text { charge tempera- } \\
\text { ture, and coal injec- } \\
\text { tion ratio }\end{array}$ & $\begin{array}{c}2100 \mathrm{t} \mathrm{day}^{-1}, 76.66 \% \\
370 \mathrm{~kg} \mathrm{t}^{-1}, 82.28 \%, 298 \mathrm{~K}, \\
\text { and } 170 \mathrm{~kg} \mathrm{t}^{-1}\end{array}$ \\
\hline Liquid & $\begin{array}{c}{[\mathrm{C}],[\mathrm{Si}],[\mathrm{S}],[\mathrm{P}],} \\
\text { and }[\mathrm{Mn}] \text { content in } \\
\text { hot metal }\end{array}$ & $\begin{array}{c}4.6,0.5,0.025,0.084 \\
\text { and } 0.15 \%\end{array}$ \\
\hline
\end{tabular}

Table IV. The operating parameters of the oxygen blast furnace for the basic case in the GF-FOBF process

\begin{tabular}{|c|c|c|}
\hline Phases & $\begin{array}{c}\text { Operating } \\
\text { Parameters } \\
\end{array}$ & Values \\
\hline Gas & $\begin{array}{l}\text { Blast rate, blast } \\
\text { temperature, oxy- } \\
\text { gen concentration, } \\
\text { and top pressure }\end{array}$ & $\begin{array}{c}536.7 \mathrm{~m}^{3} \min ^{-1}, 298 \mathrm{~K} \\
90.0 \%, 1.2 \times 10^{5} \mathrm{~Pa}\end{array}$ \\
\hline Solid & $\begin{array}{l}\text { Daily output of iron, } \\
\mathrm{Fe}_{2} \mathrm{O}_{3} \text { content, coke } \\
\text { rate, fixed carbon } \\
\text { content of coke, } \\
\text { charge tempera- } \\
\text { ture, and coal injec- } \\
\text { tion ratio }\end{array}$ & $\begin{array}{l}3150 \mathrm{t} \mathrm{day}^{-1}, 76.66 \% \\
205 \mathrm{~kg} \mathrm{t}^{-1}, 82.28 \%, 298 \mathrm{~K} \\
200 \mathrm{~kg} \mathrm{t}^{-1}\end{array}$ \\
\hline Liquid & $\begin{array}{l}{[\mathrm{C}],[\mathrm{Si}],[\mathrm{S}],[\mathrm{P}],} \\
\text { and }[\mathrm{Mn}] \text { content in } \\
\text { hot metal }\end{array}$ & $\begin{array}{c}4.6 \%, 0.5 \%, 0.025 \%, 0.084 \% \\
0.15 \%\end{array}$ \\
\hline
\end{tabular}

phase can pass freely through the slag interface in the lower portion of the blast furnace.

$Q_{\mathrm{g}, \text { wall }}, Q_{\mathrm{s}, \text { wall }}=0.5 A_{\mathrm{wall}} h_{\mathrm{wall}}\left(\frac{T_{\mathrm{g}, \text { wall }}+T_{\mathrm{s}, \mathrm{wall}}}{2}-T_{\text {wall }}\right)$

where $Q_{\mathrm{g} \text {,wall }}$ and $Q_{\mathrm{s}, \text { wall }}$ are the gas and solid heat loss of the furnace wall, respectively, $\mathrm{W} ; A_{\text {wall }}$ is the furnace wall area, $\mathrm{m}^{2}$; and $T_{\mathrm{g} \text {,wall }}$ and $T_{\mathrm{s}, \text { wall }}$ are the temperatures of the gas phase and solid phase near the furnace wall, respectively, $K$. The convective heat-transfer coefficient $h_{\text {wall }}$ and the furnace wall temperature $T_{\text {wall }}$ are set to $20 \mathrm{~W} \mathrm{~m}^{-2} \mathrm{~K}^{-1}$ and $298 \mathrm{~K}$, respectively.
Because of the strong couplings among the gas, liquid, and solid phases and because each equation simultaneously requires an iterative solution, a parallel computer cluster is used to solve the model and reduce the convergence time. When the threephase continuity equation residuals are less than 0.001 , the calculation is complete.

\section{NUMERICAL SOLUTION AND OPERATION PARAMETERS}

\section{Solution Procedure}

Well-established sequential solution procedures are employed to calculate the comprehensive momentum, mass and energy transfers through the steps shown in Fig. 2. The parameters are calculated through iterations with given operational conditions.

\section{Blast Furnace Structure and Computational Grid}

In this model, the study object is a blast furnace with a hearth diameter of $6.8 \mathrm{~m}$, a height of $19.95 \mathrm{~m}$, and an effective volume of $750 \mathrm{~m}^{3}$. A bodyfitted coordinates (BFC) grid was generated in this area. The geometrical parameters and mesh distributions of the blast furnace are shown in Fig. 3. No shaft tuyeres of a traditional blast furnace were available.

\section{Operating Parameters for the Blast Furnace}

The operational results of a traditional blast furnace were calculated using the model, and the simulation results were compared with actual production data to verify the validity of the model. The main operating parameters of the actual production blast furnace are shown in Table III. On the basis of the model validation, the boundary conditions and internal parameters of the model were modified to obtain the oxygen blast furnace mathematical model. In the simulations of the oxygen blast furnace, one set of parameters was set as the base case. The operating parameters are shown in Table IV.

Two rows of tuyeres are present in the oxygen blast furnace. The recycling gas volumes, compositions, and temperatures of these tuyeres are shown in Table V. To ensure the reasonable setting of the inlet boundary conditions, all conditions were calculated by a comprehensive mathematical model established on balancing the chemical reactions and maintaining the conservation of material and energy under the corresponding operating conditions.

\section{RESULTS AND DISCUSSION}

\section{Model Validation}

To verify the validity and accuracy of the model, the model was used to calculate the parameters of a traditional blast furnace. Figure 4 shows the temperature distribution of the three phases, and the 
Table V. Recycling gas parameters for the oxygen blast furnace

\begin{tabular}{|c|c|c|c|c|c|c|c|c|}
\hline \multirow[b]{2}{*}{ Region } & \multicolumn{6}{|c|}{ Recycling Gas composition (vol.\%) } & \multirow[b]{2}{*}{ Gas volume $\left(\mathrm{m}^{3} \mathrm{t}^{-1}\right)$} & \multirow[b]{2}{*}{ Temperature $(\mathbf{K})$} \\
\hline & $\mathbf{C O}$ & $\mathrm{CO}_{2}$ & $\mathbf{H}_{2}$ & $\mathbf{H}_{2} \mathbf{O}$ & $\mathbf{O}_{2}$ & $\mathbf{N}_{2}$ & & \\
\hline Recycling gas into shaft & 80.5 & - & 8.4 & - & - & 11.1 & 358.0 & 1173 \\
\hline Recycling gas into hearth & 80.5 & - & 8.4 & - & - & 11.1 & 400.0 & 1173 \\
\hline
\end{tabular}

Table VI. Comparisons of the calculated top gas compositions and the measured values for a traditional blast furnace

\begin{tabular}{lllllll}
\hline Top gas compositions & $\underline{\mathbf{C O}}$ & $\underline{\mathbf{C O}_{\mathbf{2}}}$ & $\underline{\mathbf{H}_{2}}$ & $\underline{\mathbf{H}_{\mathbf{2}} \mathbf{O}}$ & $\underline{\mathbf{O}_{\mathbf{2}}}$ & $\frac{\mathbf{N}_{\mathbf{2}}}{52.5}$ \\
\hline Calculated values (vol.\%) & 22.5 & 20.3 & 1.5 & 3.1 & 0.1 & 53.4 \\
Measured values (vol.\%) & 21.9 & 20.2 & 1.9 & 2.3 & 0.3 & \\
\hline
\end{tabular}

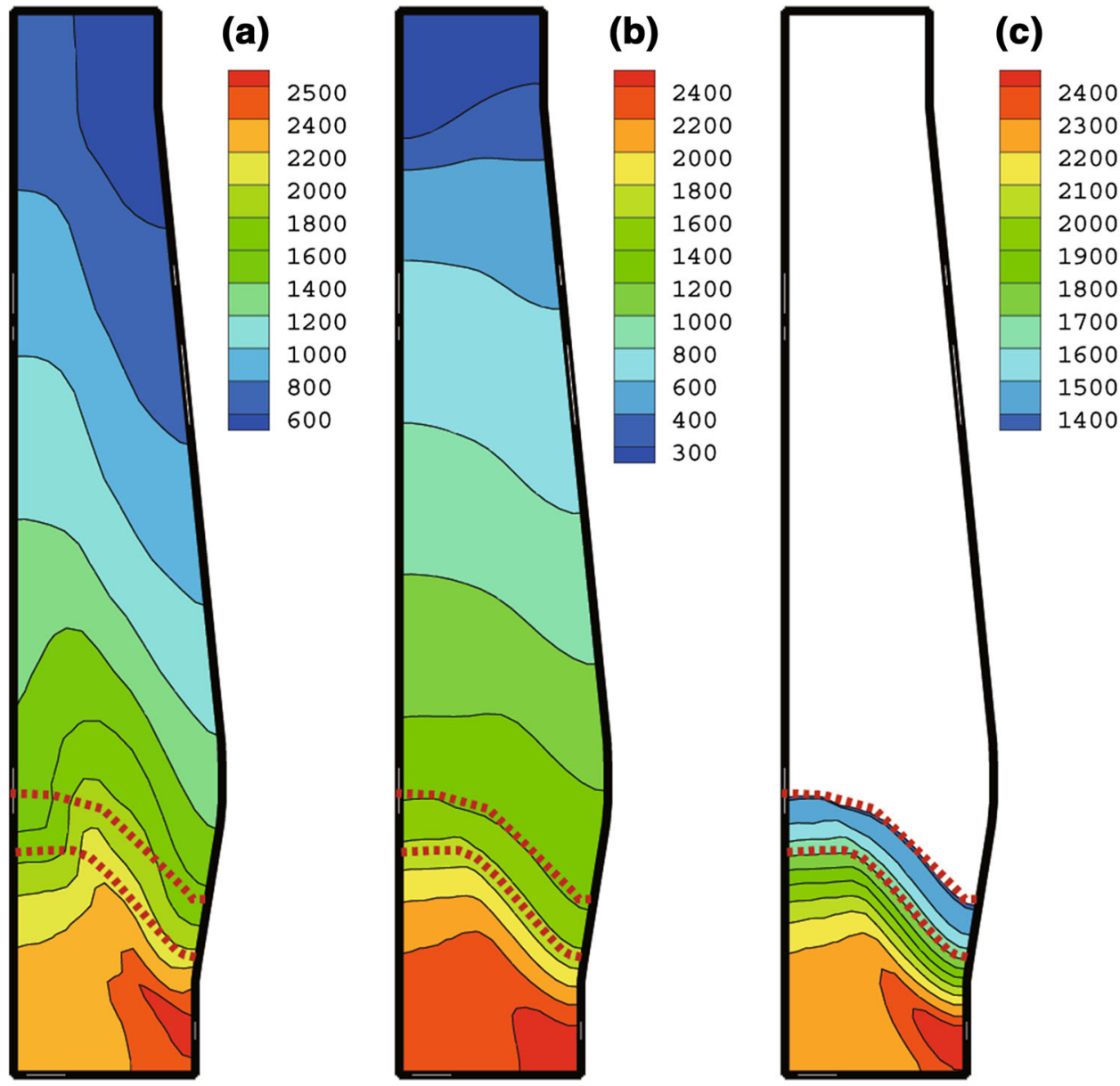

Fig. 4. (a) Gas, (b) solid, and (c) liquid temperature field in a traditional blast furnace (K).

dashed line represents the cohesive zone. From this figure, the calculated temperature fields match well with the temperature distribution trends obtained by anatomical blast furnace or other actual mea- surements. The cohesive zone displays an inverted V-shape.

The calculated top gas components were compared with the values noted during actual produc- 
tion (Table VI). Minimal differences were noted between these two sets of values, reflecting the high credibility of the calculated results of the model.
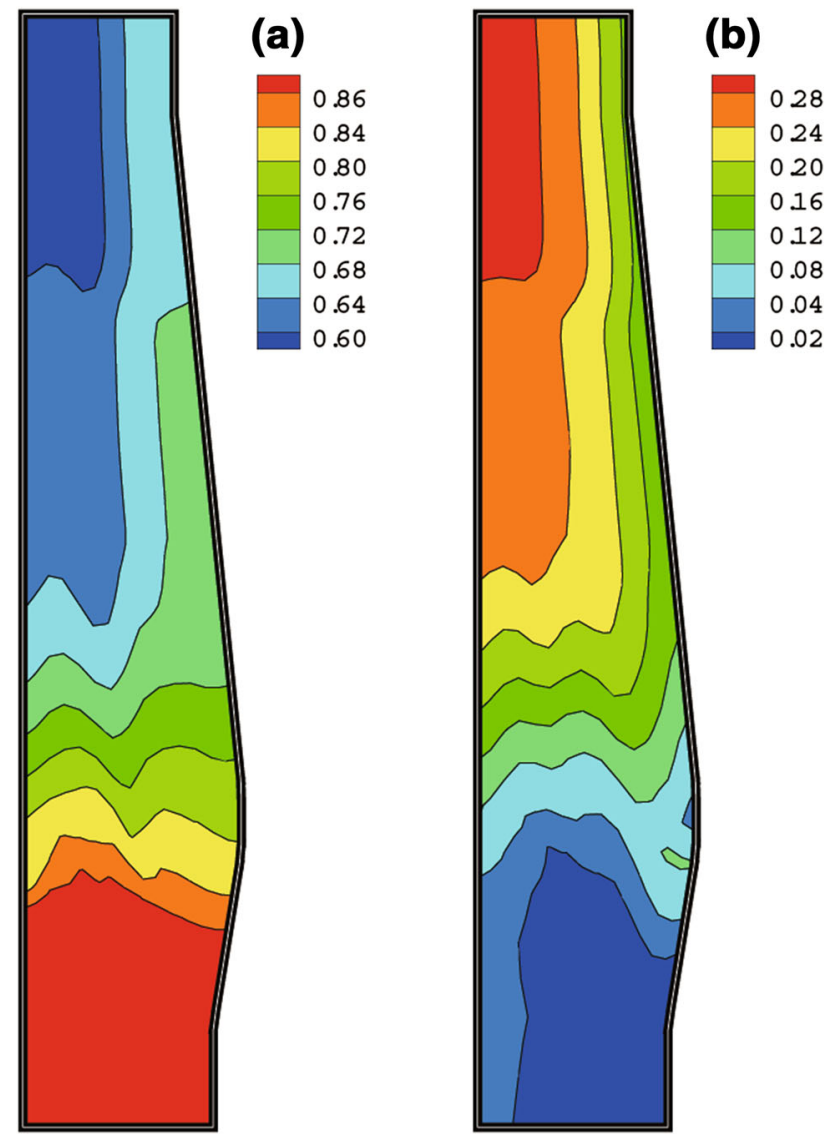

Fig. 5. Volume fraction distributions of (a) $\mathrm{CO}$ and (b) $\mathrm{CO}_{2}$ in the oxygen blast furnace.

\section{Basic Characteristics of the Gas Distribution in an Oxygen Blast Furnace}

To determine the basic characteristics of the gas distribution in an oxygen blast furnace, the base case for an oxygen blast furnace was calculated with the multifluid model. $\mathrm{CO}$ and $\mathrm{CO}_{2}$ replaced $\mathrm{N}_{2}$ as the main components of the gaseous phase in the oxygen blast furnace, and their distributions are essential to the smooth operation of the blast furnace. Therefore, $\mathrm{CO}$ and $\mathrm{CO}_{2}$ can be used to characterize the distribution of the gas phase in oxygen blast furnaces.

Figure 5 shows the calculated concentration distributions of $\mathrm{CO}$ and $\mathrm{CO}_{2}$ in the oxygen blast furnace. Below the shaft tuyere in the furnace, the contours of $\mathrm{CO}$ and $\mathrm{CO}_{2}$ are parallel to the horizontal plane and their volume fractions decrease or increase as the height increases, whereas their contours becomes parallel to the vertical direction above the shaft tuyere. In the upper and top part of the furnace, the $\mathrm{CO}$ volume fraction distribution also presents a gradually decreasing trend from the edge to the center of the furnace, whereas the $\mathrm{CO}_{2}$ volume fraction shows an opposite trend. This phenomenon mainly results from the collisions of the recycling gas injected into the blast furnace through the shaft tuyere with the charge temperature and the gas ascending from the hearth. These collisions hamper the horizontal movement of the recycling gas and promote an upward movement, causing an uneven distribution of the recycling gas.

Figure $6 \mathrm{a}$ and $\mathrm{b}$ shows the radius distributions of $\mathrm{CO}$ and $\mathrm{CO}_{2}$ at different heights above the shaft tuyere in the oxygen blast furnace used in the GFFOBF process, respectively. From this figure, the CO concentration decreases from the edge to the center at the identical height above the shaft tuyere. In addition, as the height increases, the $\mathrm{CO}$ concentration decreases, whereas the $\mathrm{CO}_{2}$ concentration shows an opposite trend. At the top of oxygen
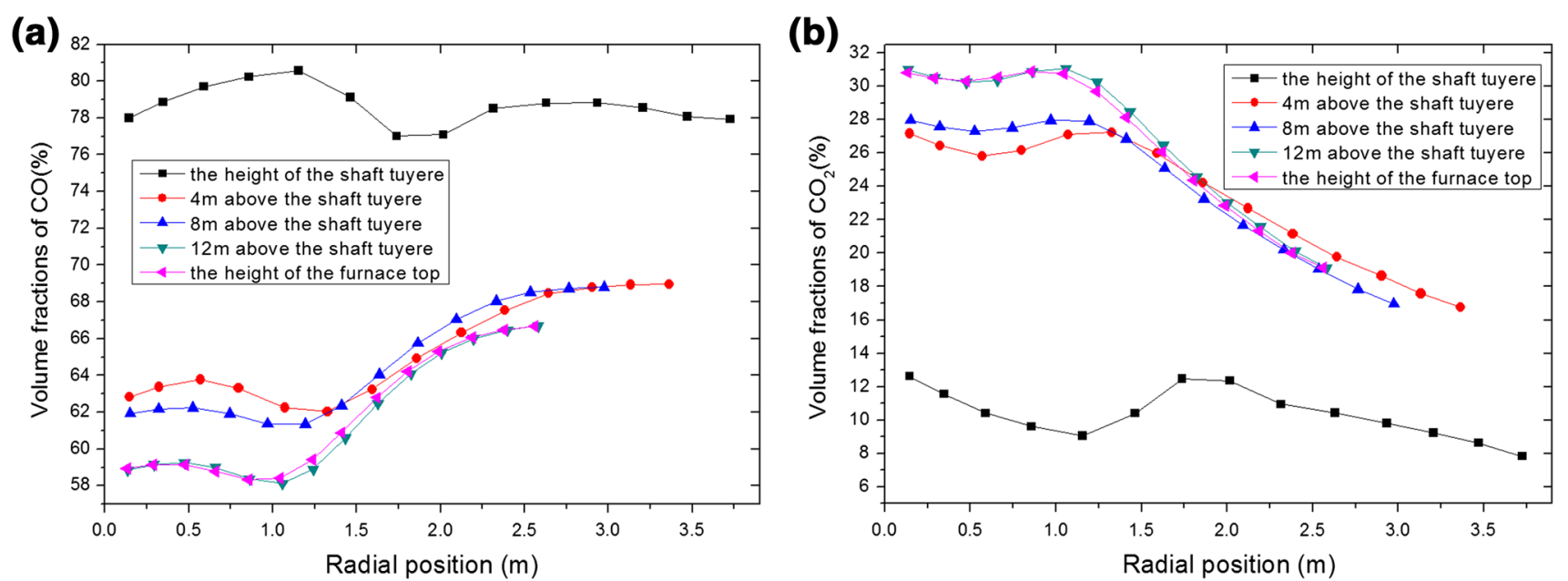

Fig. 6. Radial distributions of (a) $\mathrm{CO}$ and (b) $\mathrm{CO}_{2}$ at different heights in the oxygen blast furnace. 

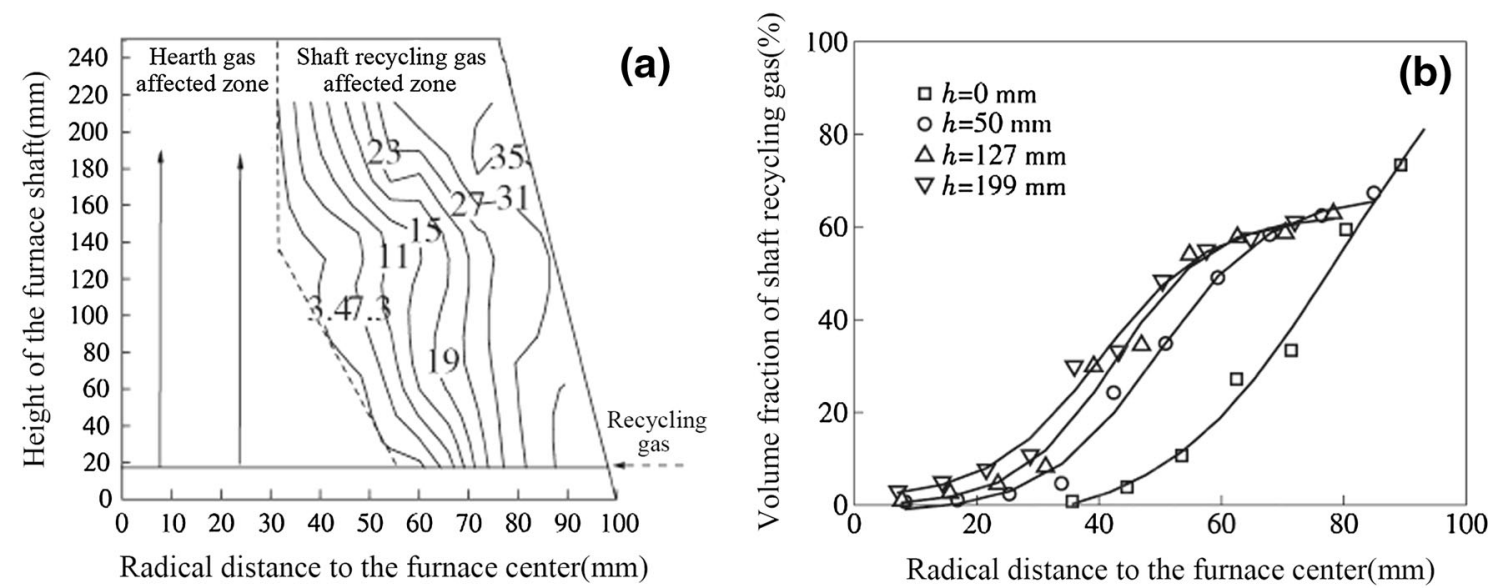

Fig. 7. The experimental results from the literature: (a) volume fraction distribution of shaft recycling in the upper furnace and (b) radial distribution of the shaft recycling gas at different heights of the furnace shaft.

blast furnace, the concentration differences of the $\mathrm{CO}$ and $\mathrm{CO}_{2}$ between center and edge reach a maximum $(7.8 \%$ and $11.7 \%$, respectively). These values can be used to represent the uneven distribution degree of the reducing gas. However, both remain stable in the central portion (the inner one third of the blast furnace). This phenomenon indicates that the recycling gas from the shaft tuyere can only penetrate to two thirds of the radial direction. Natsui et al. ${ }^{19,20}$ called the infiltration of the recycling gas toward the center the radial eddy diffusion effect; this effect results from the irregular distribution of the gas in the radial direction caused by turbulent diffusion. Because the even distribution of recycling gas is essential to reducing the burden, distributing the temperature, and utilizing the reducing gas, the magnitude of the radial eddy diffusion effect plays a significant role in the utilization of the recycling gas in an oxygen blast furnace.

To further validate the application of the oxygen blast furnace multifluid model in the study of the gas distribution, the simulation results of the gas distribution in the blast furnace was compared with the experimental results of the gas distribution in an oxygen blast furnace obtained by Liu et al. ${ }^{21}$ Figure $7 \mathrm{a}$ and $\mathrm{b}$ show the typical gas distribution in the upper furnace and the radial distributions of the recycling gas injected through the shaft tuyere in the experimental study, respectively. The volume fraction distribution trend is similar to the distribution in Fig. 5a. The recycling gas injected through the shaft tuyere is concentrated at the edge of the blast furnace. The upper part of the furnace is divided into two parts: the hearth gas-affected zone and the shaft recycling gas-affected zone. For the radial distribution of recycling gas, the experimental data measured at different heights of the furnace is similar to the radial distribution of $\mathrm{CO}$ shown in Fig. 6a. Small differences are noted because the model considers the chemical reactions and high temperatures that are ignored in this previous experiment. The similarity between the simulation results and the experimental results shows that the model is appropriate for studying the gas distribution in an oxygen blast furnace. Furthermore, the model is more accurate and comprehensive to consider completely the actual conditions.

\section{CONCLUSION}

The gas distribution in an oxygen blast furnace was studied with a recently established multifluid model. The main findings of this study are summarized as follows:

1. Because of the introduction of the shaft tuyere, the uneven distribution of the recycling gas becomes a severe problem. Below the shaft tuyere, the reducing gas is evenly distributed. However, the recycling gas is unevenly distributed above the shaft tuyere. The distributions of $\mathrm{CO}$ and $\mathrm{CO}_{2}$ can be used to demonstrate this problem.

2. The gas distribution in an oxygen blast furnace displays concentration differences of $\mathrm{CO}$ and $\mathrm{CO}_{2}$ between the center and edge at the top of the furnace, reaching $7.8 \%$ and $11.7 \%$, respectively. The recycling gas from the shaft tuyere only penetrates two thirds of the radius; i.e., the recycling gas is concentrated at the edge of the blast furnace. Therefore, the recycling gas utilization is seriously affected.

\section{ACKNOWLEDGEMENT}

This research was supported by the National Natural Science Foundation of China (Grant No. 51134008) and National Program on Key Basic Research Project of China (973 Program) (Grant No. 2012CB720401). 


\section{REFERENCES}

1. M.S. Qin and Y.T. Zhang, Ironmak. Steelmak. 15, 287 (1988).

2. R. Murai, M. Sato, and T. Ariyama, ISIJ Int. 44, 2168 (2004).

3. J.L. Meng, H.Q. Tang, and Z.C. Guo, Appl. Mech. Mater. 268, 356 (2013).

4. T. Inada, A. Kasai, K. Nakano, S. Komatsu, and A. Ogawa, ISIJ Int. 49, 470 (2009).

5. T. Iwamura, H. Sakimura, Y. Maki, T. Kawai, and Y. Asano, Trans. Iron Steel Inst. Jpn. 22, 764 (1982).

6. J. Yagi, ISIJ Int. 33, 619 (1993).

7. M.S. Chu, H. Nogami, and J. Yagi, ISIJ Int. 44, 801 (2004)

8. K. Meijer, M. Denys, J. Lasar, J.P. Birat, G. Still, and B. Overmaat, Ironmak. Steelmak. 36, 249 (2009).

9. M.S. Chu and J. Yagi, Steel Res. Int. 81, 1043 (2010).

10. M.S. Chu, X.F. Yang, F.M. Shen, J. Yagi, and H. Nogami, J. Iron. Steel Res. Int. 13, 8 (2006).
11. H. Nogami, M.S. Chu, and J. Yagi, Rev. Metall. 102, 189 (2005).

12. M.S. Chu, H. Nogami, and J. Yagi, ISIJ Int. 44, 2159 (2004).

13. S. Ergun, Chem. Eng. Prog. 48, 89 (1952).

14. J.F. Richardson and R.A. Meikle, Trans. Inst. Chem. Eng. 39, 348 (1961).

15. P.C. Carman, Chem. Eng. Res. Des. 75, S32 (1997).

16. W.E. Ranz and W.R. Marshall, Chem. Eng. Prog. 48, 141 (1952).

17. P.J. Mackey and N.A. Warner, Metall. Trans. 3, 1807 (1972).

18. E.R.G. Eckert and R.M. Drake, Heat Mass Transfer, 2nd ed (New York: McGraw-Hill Book Co., 1976), p. 173.

19. S. Natsui, S. Ueda, H. Nogami, J. Kano, R. Inoue, and T. Ariyama, ISIJ Int. 51, 1410 (2011).

20. S. Natsui, S. Ueda, H. Nogami, J. Kano, R. Inoue, and T. Ariyama, ISIJ Int. 51, 51 (2011).

21. J.Z. Liu, Q.G. Xue, X.F. She, and J.S. Wang, Beijing Keji Daxue Xuebao 36, 817 (2014). 